\title{
DANTE preparation for black-blood coronary wall imaging
}

\author{
Meihan Wang ${ }^{1 *}$, Christopher M Kramer ${ }^{2,3}$, Craig H Meyer ${ }^{1,3}$ \\ From 16th Annual SCMR Scientific Sessions \\ San Francisco, CA, USA. 31 January - 3 February 2013
}

\section{Background}

Double inversion recovery (DIR) pre-pulses combined with ECG gating are often used [1] in black blood imaging. However, the inversion time is often too long. Also, the blood suppression is often insufficient in multi-slice studies. DANTE is a novel black-blood technique that has been shown to maintain SNR and CNR similar to single-slice DIR in ungated carotid artery studies [2] and is compatible with multi-slice acquisition. In this study, we combined DANTE pulses with gating and tested the performance for coronary wall imaging.

\section{Methods}

Experiments were performed on a Siemens 3T Tim Trio scanner with a 32 channel coil array. Four volunteers (age 26-29) were tested with a multi-slice spiral gradient echo sequence with ECG gating. The sequence consisted of a $5 \mathrm{~ms}$ spectral-spatial excitation pulse followed by a $16 \mathrm{~ms}$ constant density spiral readout gradient. FOV $=240-340 \mathrm{~mm}, 14-20$ interleaves, 3 slices, each with $5 \mathrm{~mm}$, inplane resolution $0.7-0.9 \mathrm{~mm}$. DANTE prepulses were placed before the imaging readout with spacing $=0.6 \mathrm{~ms}$ and flip angle $=7$. A similar sequence
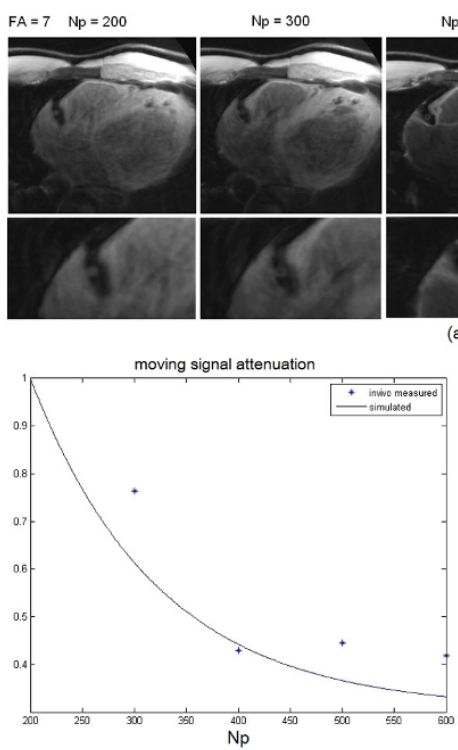

(b)
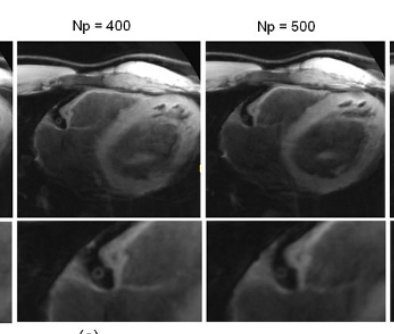

$N p=600$

(a)

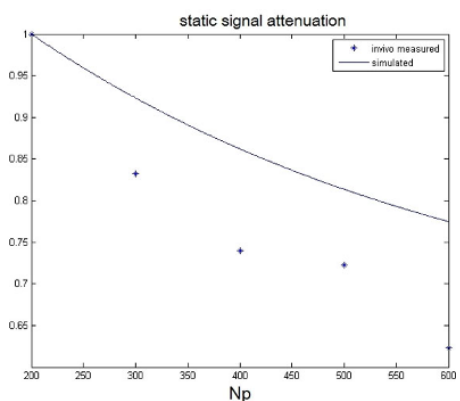

(c),

Figure 1 (a) RCA wall images acquired with DANTE preparation, with number of pulses $=200,300,400,500$ and 600 and flip angle $=7$. (b) Simulated and experimental signal attenuation of moving spin using the DANTE preparation. (c) Simulated and experimental signal attenuation of static spin using the DANTE preparation.

'Biomedical Engineering, University of Virginia, Charlottesville, VA, USA

Full list of author information is available at the end of the article

(c) 2013 Wang et al; licensee BioMed Central Ltd. This is an Open Access article distributed under the terms of the Creative Commons 


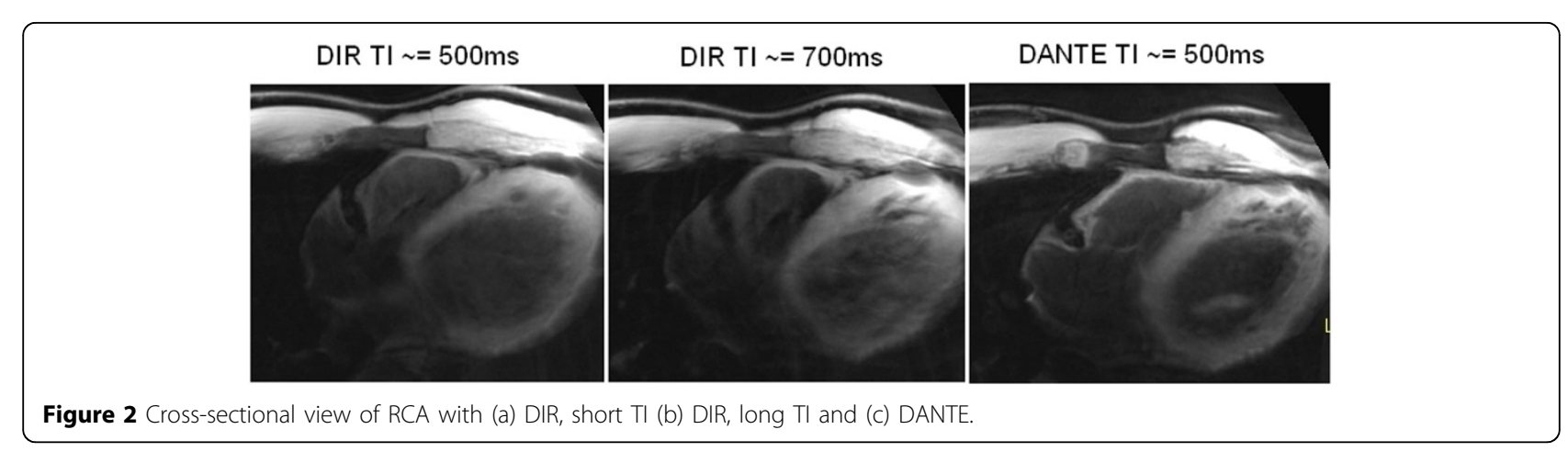

with double inversion pre-pulses was used for comparison.

\section{Results}

As shown in Fig. 1, the blood suppression improved as the number of pulses (Np) increased from 200 to 600, but there was increasing attenuation of the wall signal. The best contrast between wall and lumen was achieved when $=400-500$. There was good agreement between the measured and simulated blood suppression, as shown in Fig. 1 (b). Fig.1(c) shows that the vessel wall signal experiences extra attenuation because of motion.

For some subjects, the rest period occurred before middiastole, which left unsuppressed blood when using DIR, as shown in Fig. 2(a). Figure 2(b) shows the result using DIR with a longer inversion time. The image has better blood suppression, but the coronary wall is severely blurred by motion of the RCA. As shown in Fig. 2(c), DANTE pulses enable a better balance between nulling blood and reducing motion blur.

The mean SNR and CNR of the coronary wall was 14.9 $+/-3.8$ and 5.5+/-3.1 for images with DANTE pulses, and $16.7+/-3.7$ and $5.1+/-3.0$ for DIR prepared images. DIR achieved a slightly higher SNR but lower CNR because of unsuppressed blood induced by the short TI $(\mathrm{p}<0.05)$.

\section{Conclusions}

We have developed a cardiac-gated DANTE black blood technique for coronary artery imaging. DANTE pulses give comparable SNR to double inversion recovery, but with more flexible imaging. This method can be adapted for other black blood cardiac applications.

\section{Funding}

This study was funded by NIH R01 HL079110 and Siemens Medical Solutions.

\section{Author details}

${ }^{1}$ Biomedical Engineering, University of Virginia, Charlottesville, VA, USA. ${ }^{2}$ Medicine, University of Virginia, Charlottesville, VA, USA. ${ }^{3}$ Radiology, University of Virginia, Charlottesville, VA, USA.
Published: 30 January 2013

doi:10.1186/1532-429X-15-S1-P237

Cite this article as: Wang et al:: DANTE preparation for black-blood coronary wall imaging. Journal of Cardiovascular Magnetic Resonance 2013 15(Suppl 1):P237.

\section{Submit your next manuscript to BioMed Central and take full advantage of:}

- Convenient online submission

- Thorough peer review

- No space constraints or color figure charges

- Immediate publication on acceptance

- Inclusion in PubMed, CAS, Scopus and Google Scholar

- Research which is freely available for redistribution
Biomed Central 